\title{
Progression of diabetic nephropathy and associated factors in a cohort of Sri Lankan patients: a retrospective study
}

\author{
Wanigasuriya $\mathbf{K}^{1,2}$, Galahitiyawa $\mathbf{C}^{3}$, de Silva $\mathbf{P}^{4}$, Ranasinghe $\mathbf{P}^{5}$, Herath $\mathbf{C}^{3}$ \\ Journal of the Ceylon College of Physicians, 2021, 52, 78-86
}

\begin{abstract}
Background: Previous studies have noted a marked racial/ethnic difference in epidemiology and progression of diabetic nephropathy. The present study aims to examine the rate of decline in estimated GFR (eGFR) and factors associated with progression in a cohort of patients with DN in Sri Lanka.
\end{abstract}

Methods: A retrospective-cohort-study was conducted among patients with diabetic nephropathy. Data were collected retrospectively for 2-years by perusal of clinic records, including socio-demographic details, co-morbidities, investigational results, and details of medications. eGFR was calculated and staging was based on National Kidney Foundation Kidney Disease Outcomes Quality Initiative criterion.

Results: One hundred and fifty-five adults were included (men-20.3\%). Mean age was 66.5 \pm 8.7 years. Mean duration of diabetes was 18.2 \pm 8.9 years, while diabetic retinopathy was the commonest microvascular complication (>90.0\%). Majority were in either stage $3(36.8 \%)$ or stage 4 $(40.6 \%)$ CKD at recruitment. During the two-year period eGFR declined in 93 patients $(60.0 \%)$, with a mean decline in eGFR of $5.2 \mathrm{ml} / \mathrm{min} / 1.73 \mathrm{~m}^{2}$ per year. There were 31 patients $(20.0 \%)$ with rapid decline in eGFR (>5 $\mathrm{ml} / \mathrm{min} / 1.73 \mathrm{~m}^{2}$ per year). Those with declining eGFR were significantly older $(p<0.001)$. Decline in renal function was significantly associated with presence of albuminuria (OR:4.9; $\mathrm{p}<0.001$ ).

Conclusion: A rapid decline in kidney function was observed in the present study population, with implications for negative long-term consequences for both the individual patients and the health care system. Therefore, it is an important factor that should be considered when taking policy decisions in relation to future preventive and curative health care planning.

Key words: diabetic nephropathy, microvascular complication, diabetes mellitus, Sri Lanka

\section{Introduction}

The prevalence of diabetes has been rapidly increasing around the world in recent years, becoming a global pandemic. The number of people with diabetes rose from 108 million in 1980 to 463 million in 2019 and is expected to increase by a further $150 \%$, affecting nearly 700 million adults by the year $2045 .{ }^{1}$ Diabetes can lead to the development of several macro- and micro-vascular diseases, which further increases morbidity and mortality. Diabetic nephropathy (DN) is one such common micro-vascular disease accounting for approximately one third of the chronic kidney disease patients referred for renal replacement therapy globally. ${ }^{2,3}$ Renal disease is known to affect nearly

${ }^{1}$ Center for Kidney Research, University of Sri Jayewardenepura, Sri Lanka, ${ }^{2}$ Department of Medicine, Faculty of Medical Sciences, University of Sri Jayewardenepura, Sri Lanka, ${ }^{3}$ Sri Jayewardenepura General Hospital, Sri Lanka, ${ }^{4}$ Ministry of Health, Sri Lanka, ${ }^{5}$ Department of Pharmacology, Faculty of Medicine, University of Colombo, Colombo, Sri Lanka

Correspondence: KW, E-mail: kamaniw@sjp.ac.lk

https://orcid.org/0000-0002-2826-6199

Received 10 October 2021, accepted 30 November 2021.

This is an open-access article distributed under the terms of the Creative Commons Attribution License, which permits unrestricted use, distribution, and reproduction in any medium, provided the original author and source are credited. 
20 to $40 \%$ of individuals with type- 2 diabetes during their lifetime. ${ }^{4} \mathrm{DN}$ is characterized by proteinuria, gradual and irreversible decline in glomerular filtration rate (GFR), hypertension and high risk of cardiovascular disease. $^{4}$

Previous studies have noted a marked racial/ ethnic difference in the epidemiology of DN and its progression. For example, a longitudinal cohort study among 429,918 veterans with diabetes, showed that African Americans, Asians and Native Americans were more likely to develop DN than Caucasians. ${ }^{5}$ Furthermore, the rate of decline in GFR is also known to be highly variable, with progressive kidney disease being more frequent in Caucasians with diabetes mellitus. ${ }^{4}$ Several strategies including optimal glycaemic control, blood pressure control and ACEI therapy have been implicated as effective measures at slowing down the progression of $\mathrm{DN}$ and reducing cardiovascular disease in patients with DN.,7 Microalbuminuria is recognized as a marker of early glomerular involvement, with studies showing that $35-40 \%$ will progress to macroalbuminuria with time. ${ }^{8}$

With the rising prevalence of diabetes in South Asian populations, it is expected that DN will also increase causing a significant burden on the scarce health resources of these developing nations. ${ }^{9}$ Sri Lanka is a lower-middle-income developing nation in the South Asian region, faced with a significant burden of diabetes. ${ }^{10,11}$ In Sri Lanka, the main emphasis at present is on chronic kidney disease of unknown aetiology (CKDu) which affects the poor farming communities in the North Central regions of the country. ${ }^{12}$ However, with the rising prevalence of diabetes, it can be expected that the perceived prevalence of DN will rise in epidemic proportions. Although several studies have examined the progression of DN in western countries, it is noteworthy that individual and racial differences exist in progression and the risk factors that determine disease outcome and complications. ${ }^{13}$ An understanding of the DN, its progression and the risk of developing the end stage renal disease is critical when projecting future disease burden and providing renal replacement facilities. This is especially important in Sri Lanka where the facilities for management of end-stage renal disease is limited due to constraints on health care expenditure. The present study aims to examine the rate of decline in eGFR and the effects of gender, age, hypertension and other related factors on the progression of decline in a cohort of patients with DN in Sri Lanka.

\section{Methods}

\section{Study population}

This retrospective single center cohort study was conducted among patients followed up at the Renal Clinic, Sri Jayewardenepura General Hospital (SJGH), Sri Lanka from October 2017 to January 2018. The SJGH is a 1,000-bed tertiary care referral hospital situated in Sri Jayewardenepura Kotte, Sri Lanka. Patients attending the renal clinic were screened to identify patients diagnosed with $\mathrm{DN}$, based on renal impairment, persistent albuminuria, with co-existing retinopathy or peripheral neuropathy and no evidence of alternative kidney disease. ${ }^{14}$ Patients without microvascular disease was considered for inclusion if they had renal biopsy proven DN. These details were verified by perusal of clinical records by a trained research assistant supervised by an investigator (CG). For the purpose of retrospective data collection, those who had regular clinic attendance with follow up retrospective data for two years from the date of screening were considered eligible. Patients who had End Stage Kidney Disease (ESKD) who were on renal replacement therapy at screening were excluded. Ethics approval for the study was obtained from the Ethics Review Committee, Sri Jayewardenepura General Hospital. Informed written consent was obtained from study participants prior to inclusion in the study.

\section{Data collection and Definitions}

Data on DN and its associated details were obtained by perusal of medical records by the research assistant and was double checked for consistency and accuracy by an investigator (CG). Summarized anonymized data were collected onto an individual case record form, including socio-demographic details (age, gender, ethnicity, level of education, monthly income), co-morbidities (hypertension, ischaemic heart disease, retinopathy, and neuropathy), smoking status and investigation results (serum creatinine, albuminuria with dipstick, lipids, haemoglobin, calcium, phosphorus, and glycosylated haemoglobin (HbA1c\%)). Details of medications were also recorded including the use of hypoglycemic agents, angiotensin converting enzyme inhibitors (ACEIs), angiotensin-2 receptor blockers (ARBs), other anti-hypertensive medications and lipid lowering medications. The above data on blood pressure, medications, investigations were collected retrospectively from clinic records from data of screening backwards for 2 years from date of recruitment. Seated blood pressure was recorded at recruitment visit on two occasions after at least a 10-min rest using an Omron IA2 digital blood pressure 
monitor (Omron Healthcare, Asia-Pacific Region, Singapore). Height was measured using Harpenden pocket stadiometers (Chasmors Ltd, London, UK) to the nearest $0.1 \mathrm{~cm}$ according to standard methods. Body weight was measured to the nearest $0.1 \mathrm{~kg}$ using a SALTER 920 digital weighing scale (Salter Ltd, Tonbridge, UK). Body mass index (BMI) was calculated as weight in kilograms per square meter of height $\left(\mathrm{kg} / \mathrm{m}^{2}\right)$.

\section{Statistical analysis}

Data were analysed using SPSS statistical software package. Estimated GFR (eGFR) was calculated by CKD-EPI (Chronic Kidney Disease Epidemiology Collaboration) equation.15 and staging was done based on the National Kidney Foundation Kidney Disease Outcomes Quality Initiative (NKF KDOQI) criterion.16 The rate of eGFR fall per year was used to assess the progression of DN and calculated by the difference in eGFR $\left(\mathrm{mL} / \mathrm{min} / 1.73 \mathrm{~m}^{2}\right)$ at presentation and the last available reading divided by the duration. Continuous variables are expressed as means \pm SD and compared using the student's t-test (parametric distribution) or the Mann-Whitney $U$ test (non-parametric distribution). Categorical variables are expressed as proportions and compared with the chi-square test.

\section{Results}

\section{Socio-demographic and disease characteristics}

One hundred and fifty-five adults were included in the study. Mean age was 66.5 \pm 8.7 years (range $40-88$ years) and majority were men $(n=109 ; 70.3 \%)$. Study population characteristics are summarized in Table 1. Majority were Sinhalese in ethnicity $(n=141 ; 91.0 \%)$ and educated beyond GCE O/L $(n=112 ; 72.3 \%)$. Mean BMI was $26.7 \pm 4.2 \mathrm{~kg} / \mathrm{m}^{2}$, with women having a significantly higher BMI than men (Table 1). Hypertension was a common co-morbid disease among the participants $(n=148 ; 95.5 \%)$, and mean duration of hypertension in the study population was $8.97 \pm 8.14$ years. ARBs $(n=83 ; 53.5 \%)$ and calcium channel blocker (CCBs) ( $n=67 ; 43.2 \%)$, were the most used anti-hypertensive medications, while most were on statin therapy for primary/secondary prevention $(n=114$; $73.5 \%$ ). There was no significant difference between characteristics of men and women, except with regards to monthly income, smoking, BMI, ACEI therapy and statin therapy (Table 1).

Mean duration of diabetes in the study population was $18.2 \pm 8.9$ years, being significantly longer in men than in women (Table 2). Only 14 participants have undergone renal biopsy for the diagnosis of diabetic nephropathy $(9.0 \%)$. Diabetic retinopathy was the commonest microvascular complication, being identified in $>90.0 \%$ of the study participants, and significantly more in men than in women (Table 2). Family history of diabetes in a first degree relative was noted to be present in 59.3\% ( $n=92)$, while $13.6 \%$ $(n=21)$ had family history of DN. Past history of at least one episode of urinary tract infection requiring treatment was present in 51.6\% $(n=81)$, while $19.4 \%$ $(n=30)$ acknowledged that they have taken native/herbal medications for diabetes and/or diabetic nephropathy. In participants where data were available the mean $\mathrm{HbA1C}$ and fasting blood glucose at the time of recruitment were $8.1 \pm 1.5 \%(n=61)$ and $124.4 \pm 40.4 \mathrm{mg} /$ dl $(n=148)$ respectively.

\section{Changes in kidney function and associated factors}

The mean serum creatinine and eGFR at time of recruitment were $2.6 \pm 1.1 \mathrm{mg} / \mathrm{dl}$ and $28.2 \pm 14.0 \mathrm{ml} / \mathrm{hour}$ respectively, while albuminuria was present in $54.8 \%$ $(n=85)$. CKD staging based on eGFR at time of recruitment and 24 months before recruitment are shown in Table 3. Majority of the participants were in either stage $3(36.8 \% ; n=57)$ or stage $4(40.6 \%$; $n=63)$ CKD at recruitment. Similarly, when participants were classified in to CKD stages based on eGFR 2 years prior to the date of recruitment, majority were in stage $3(43.2 \%)$ and stage 4 CKD (43.2\%) (Table 3). When changes in eGFR was evaluated, there was no change in 8 patients (5.2\%), while eGFR declined in 93 patients $(60.0 \%)$, and improved in the remaining patients $(n=54 ; 34.8 \%)$ during the 24 -month retrospective evaluation period. In patients with declining eGFR ( $n=93)$, the mean decline in eGFR per year was $5.2 \mathrm{ml} / \mathrm{min} / 1.73 \mathrm{~m}^{2}$ (Range $0.5-33 \mathrm{ml} / \mathrm{min} / 1.73 \mathrm{~m}^{2}$ per year). There were 31 patients $(20.0 \%)$ with rapid decline in eGFR (a decline in eGFR of $>5 \mathrm{ml} / \mathrm{min} /$ $1.73 \mathrm{~m} 2$ per year), which comprised of $33.3 \%$ of patients when considering only those with declining eGFR. The percentage decline in eGFR was less than or equal to $20 \%$ in $37.6 \%(n=35)$, between $20.1-30 \%$ in $23.6 \%$ $(n=22)$, between $30.1-40 \%$ in $15.0 \%(n=11)$, between $40.1-50 \%$ in $11.8 \%(n=11)$ and more than $50 \%$ in $11.8 \%$ $(n=11)$. Figure 1 shows the average decline in eGFR with time among study participants. In those with improved eGFR $(n=54)$, the mean increase in eGFR per year was $3.4 \mathrm{ml} / \mathrm{min} / 1.73 \mathrm{~m}^{2}$ (Range 0.5-26.5 $\mathrm{ml} / \mathrm{min} / 1.73 \mathrm{~m}^{2}$ per year). The percentage increase in eGFR was less than or equal to $20 \%$ in $61.1 \%$ $(n=33)$, between $20.1-30 \%$ in $11.1 \%(n=6)$, between $30.1-40 \%$ in $7.4 \%(n=4)$, between $40.1-50 \%$ in $5.6 \%$ $(n=3)$ and more than $50 \%$ in $14.8 \%(n=8)$.

There was no significant gender difference associated with decline in eGFR (men $67.0 \%$ and women $60.8 \% ; p=0.47$ ). Those with declining eGFR 
(42.9 \pm 3.2 years) were significantly older than those who had unchanged/improving eGFR (23.6 \pm 3.2 years) $(p<0.001)$. In those with declining renal function $(n=93)$, there was no significant correlation observed between the decline in eGFR and the duration of diabetes $(r=0.11 ; p=0.29)$. Smokers (both current and past) were not more likely to have a decline in kidney function than non-smokers (OR: 1.3, 95\% Cl 0.6 - 2.6; $\mathrm{p}=0.52$ ). The presence of hypertension (OR: 1.1; $95 \% \mathrm{Cl} 0.2-5.2$; $\mathrm{p}=1.0$ ), ischaemic heart disease (OR: $0.9 ; 95 \% \mathrm{Cl} 0.5$ $-1.7 ; p=0.90$ ), retinopathy (OR: $1.1 ; 95 \% \mathrm{Cl} 0.4-3.5$; $\mathrm{p}=0.80$ ) or neuropathy (OR: $1.2 ; 95 \% \mathrm{Cl} 0.6-2.3$; $\mathrm{p}=0.55)$ was not significantly associated with decline in renal function. Decline in eGFR was not associated with a past history of urinary tract infection or the use of native/herbal medications for diabetes and/or diabetic nephropathy. Furthermore, in those with declining renal function ( $n=93)$, there was no significant correlation observed between decline in eGFR and duration of hypertension $(r=0.10 ; p=0.33)$. The average systolic blood pressure during the 24-month period was not significantly different between those with (147.1 \pm 14.5 $\mathrm{mmHg})$ and without $(144.8 \pm 16.5 \mathrm{mmHg}$ ) a decline in eGFR ( $p=0.37)$. Average systolic blood pressure was $<140 \mathrm{mmHg}$ in only 25 participants $(26.9 \%)$ with a decline in eGFR, while it was $<130 \mathrm{mmHg}$ in only 14 participants (15.0\%) and the corresponding number of participants in those without a decline in eGFR was 22 (35.5\%) and 9 (14.5\%) respectively. A similar result was observed with average diastolic blood pressure $(80.6 \pm 7.5 \mathrm{mmHg}$ Vs. $79.0 \pm 8.6 \mathrm{mmHg} ; \mathrm{p}=0.23)$. Furthermore, the average fasting blood glucose values during the 24-month period was not significantly different between those with $(128.3 \pm 35.6 \mathrm{mg} / \mathrm{dl})$ and without $(127.4 \pm 29.9 \mathrm{mg} / \mathrm{dl})$ a decline in eGFR $(p=0.87)$. Decline in renal function was significantly associated with the presence of albuminuria (OR: 4.9; 95\% Cl 2.4 $-9.7 ; p<0.001)$.

When evaluating the relationship between the decline in kidney function and medications, there was no significant difference observed with the use of metformin (OR: 0.5; 95\% Cl 0.2-1.7; $p=0.29$ ), sulphonylureas (OR: 0.6; 95\% Cl 0.3-1.1; $\mathrm{p}=0.09$ ), sitagliptin (OR: $0.8 ; 95 \% \mathrm{Cl} 0.4-1.5 ; \mathrm{p}=0.51$ ), insulin (OR: 0.9; 95\% Cl 0.5-1.8; $p=0.84$ ), ACEIs/ARBs (OR: 1.0; 95\% Cl 0.5-2.0; $p=0.9$ ), CCBs (OR: 0.9; 95\% Cl 0.5-1.9; $\mathrm{p}=0.92$ ), beta blockers (OR: $1.095 \% \mathrm{Cl} 0.5-2.1 ; \mathrm{p}=1.0$ ), statins (OR: $0.9 ; 95 \% \mathrm{Cl} 0.4-2.0 ; \mathrm{p}=0.89$ ) or aspirin (OR: $1.4 ; 95 \% \mathrm{Cl} 0.7-2.6 ; \mathrm{p}=0.36$ ). Furthermore, in those with a decline in kidney function $(n=93)$, the rate of decline in eGFR over the 24-month period was similar between those who were prescribed the above individual medications and those who were not (data not shown). In those with decline in renal function, rapid decline was significantly associated only with the presence of proteinuria (OR: $3.9 ; 95 \% \mathrm{Cl} 1.2-12.8$; $\mathrm{p}=0.015)$.

Table 1. Study population characteristics

\begin{tabular}{|c|c|c|c|c|}
\hline & \multicolumn{4}{|c|}{ Number of adults (\%)* } \\
\hline & All adults & Men & Women & $p$ value ${ }^{\#}$ \\
\hline & $(n=155)$ & $(n=109)$ & $(n=46)$ & \\
\hline Age (years) & $66.5 \pm 8.7$ & $67.0 \pm 8.8$ & $65.4 \pm 8.6$ & 0.29 \\
\hline \multicolumn{5}{|l|}{ Ethnicity } \\
\hline Sinhalese & $141(91.0)$ & $102(93.6)$ & $39(84.8)$ & 0.08 \\
\hline Tamil & $3(1.9)$ & $3(2.8)$ & 0 & - \\
\hline Muslim & $3(1.9)$ & $2(1.8)$ & $1(2.2)$ & 0.88 \\
\hline Other & $8(52)$ & $2(1.8)$ & $6(13.0)$ & 0.003 \\
\hline \multicolumn{5}{|l|}{ Level of education } \\
\hline Less than grade 6 & $9(5.8)$ & $6(5.5)$ & $3(6.5)$ & 0.80 \\
\hline Grade 6-11 & $34(21.9)$ & $22(20.2)$ & $12(26.1)$ & 0.42 \\
\hline Completed GCE O/L & $55(35.5)$ & $40(36.7)$ & $15(32.6)$ & 0.63 \\
\hline Completed GCE A/L or & $57(36.8)$ & $41(37.6)$ & $16(34.8)$ & 0.74 \\
\hline \multicolumn{5}{|l|}{ Monthly income (LKR) } \\
\hline Less than LKR 10,000 & $19(12.3)$ & $9(8.3)$ & $10(21.7)$ & 0.02 \\
\hline$>=\operatorname{LKR} 10,000$ & $136(87.7)$ & $100(91.7)$ & $36(78.3)$ & 0.02 \\
\hline
\end{tabular}




\begin{tabular}{|c|c|c|c|c|}
\hline \multirow[b]{2}{*}{ Age (years) } & \multicolumn{4}{|c|}{ Number of adults (\%)* } \\
\hline & $\begin{array}{c}\text { All adults } \\
(n=155)\end{array}$ & $\begin{array}{c}\text { Men } \\
(n=109)\end{array}$ & $\begin{array}{c}\text { Women } \\
(n=46)\end{array}$ & p Value\# \\
\hline \multicolumn{5}{|l|}{ Smoking status } \\
\hline Never smoked & $108(69.7)$ & $62(56.9)$ & $46(100)$ & $<0.0001$ \\
\hline Current smoker & $2(1.3)$ & $2(1.8)$ & 0 & 0 \\
\hline Former smoker & $45(29.0)$ & $45(41.3)$ & 0 & - \\
\hline Body mass index $\left(\mathrm{kg} / \mathrm{m}^{2}\right)$ & $26.7 \pm 4.2$ & $26.2 \pm 4.2$ & $27.9 \pm 4.3$ & 0.02 \\
\hline \multicolumn{5}{|l|}{ Blood pressure (mmHg) } \\
\hline Systolic blood pressure & $149.0 \pm 18.8$ & $147.6 \pm 19.0$ & $152.7 \pm 17.8$ & 0.12 \\
\hline Diastolic blood pressure & $80.2 \pm 11.4$ & $80.4 \pm 10.2$ & $80.0 \pm 13.8$ & 0.84 \\
\hline \multicolumn{5}{|l|}{ Co-morbid diseases } \\
\hline Hypertension & $148(95.5)$ & 105 (96.3) & $43(93.5)$ & 0.43 \\
\hline Cardiovascular disease & $60(38.7)$ & $44(40.4)$ & $16(34.5)$ & 0.51 \\
\hline \multicolumn{5}{|l|}{ Current medications } \\
\hline Angiotensin converting enzyme inhibitors & $22(14.2)$ & $20(18.3)$ & $2(4.3)$ & 0.02 \\
\hline Angiotensin-II receptor blockers & $83(53.5)$ & $60(55.0)$ & $23(50.0)$ & 0.56 \\
\hline Anti-platelets & $72(46.4)$ & $53(48.6)$ & $19(41.3)$ & 0.40 \\
\hline Beta blockers & $40(25.8)$ & $27(24.8)$ & $13(28.3)$ & 0.65 \\
\hline Calcium channel blockers & $67(43.2)$ & $46(42.2)$ & $21(45.6)$ & 0.69 \\
\hline Statins & $114(73.5)$ & $74(67.9)$ & $40(86.9)$ & 0.01 \\
\hline
\end{tabular}

* Except for age, body mass index and blood pressure which are displayed as mean \pm standard deviation; \# $\mathrm{p}$ Value comparing males and females; A/L - Advanced Level; GCE - General Certificate of Education; O/L - Ordinary Level; SLR - Sri Lankan Rupee (1 SLR = approximately 0.005 US\$);

Table 2. Diabetes status, treatment and associated factors

\begin{tabular}{|c|c|c|c|c|}
\hline & \multicolumn{3}{|c|}{ Number of adults (\%)* } & \multirow[t]{2}{*}{$p$ Value ${ }^{\#}$} \\
\hline & $\begin{array}{c}\text { All adults } \\
(n=155)\end{array}$ & $\begin{array}{l}\text { Males } \\
(n=109)\end{array}$ & $\begin{array}{c}\text { Females } \\
(n=46)\end{array}$ & \\
\hline Duration of diabetes (years) & $18.2 \pm 8.9$ & $28.5 \pm 2.1$ & $19.0 \pm 14.1$ & $<0.001$ \\
\hline \multicolumn{5}{|l|}{ Microvascular complications } \\
\hline Retinopathy & $141(91.0)$ & $103(94.5)$ & $38(82.6)$ & 0.02 \\
\hline Neuropathy & $82(55.7)$ & $56(51.4)$ & $26(56.5)$ & 0.56 \\
\hline \multicolumn{5}{|l|}{ Diabetes treatment } \\
\hline Insulin & $76(49.0)$ & $49(44.9)$ & $27(58.7)$ & 0.12 \\
\hline Metformin & $13(8.4)$ & $9(8.2)$ & $4(8.7)$ & 0.93 \\
\hline Sulphonylurea & $95(61.3)$ & $71(65.1)$ & $24(52.2)$ & 0.13 \\
\hline DPP-4 inhibitors & $80(51.6)$ & $48(44.0)$ & $32(69.6)$ & 0.004 \\
\hline
\end{tabular}

* Except for duration of diabetes which is displayed as mean \pm standard deviation; \# $\mathrm{p}$ Value comparing males and females; DPP-4 - Dipeptidyl-peptidase 4 
Table 3. CKD staging based on eGFR at recruitment and 24 months before

\begin{tabular}{|c|c|c|c|c|c|c|}
\hline \multirow{3}{*}{ CKD staging } & \multicolumn{6}{|c|}{ Number (\%) } \\
\hline & \multicolumn{2}{|c|}{$\begin{array}{l}\text { All adults } \\
(n=155)\end{array}$} & \multicolumn{2}{|c|}{$\begin{array}{c}\text { Men } \\
(n=109)\end{array}$} & \multicolumn{2}{|c|}{$\begin{array}{c}\text { Women } \\
(n=46)\end{array}$} \\
\hline & T-24 months & Recruitment & T-24 months & Recruitment & T-24 months & Recruitment \\
\hline Stage 1 & $2(1.3)$ & $1(0.6)$ & $1(0.9)$ & $1(0.9)$ & $1(2.2)$ & 0 \\
\hline Stage 2 & $8(5.2)$ & $4(2.6)$ & $5(4.6)$ & $2(1.8)$ & $3(6.5)$ & $2(4.3)$ \\
\hline Stage 3 & 67 (43.2) & $57(36.8)$ & $43(39.4)$ & 37 (33.9) & $24(52.2)$ & $20(43.5)$ \\
\hline Stage 4 & 67 (43.2) & $63(40.6)$ & $54(49.5)$ & $51(46.8)$ & $13(28.3)$ & $12(26.1)$ \\
\hline Stage 5 & 11 (7.1) & $30(19.4)$ & $6(5.5)$ & $18(16.5)$ & 5 (10.9) & $12(26.1)$ \\
\hline
\end{tabular}

CKD - Chronic Kidney Disease; eGFR - estimated Glomerular Filtration Rate; T-24 months - 24 months before recruitment

Stage 1- eGFR >=90 mL/min/1.73 m², Stage 2 -eGFR 60-89 mL/min/1.73 m², Stage 3- eGFR 30-59 mL/min/1.73 m², Stage 4- eGFR 15-29 $\mathrm{mL} / \mathrm{min} / 1.73 \mathrm{~m}^{2}$, Stage 5 - eGFR $<15 \mathrm{~mL} / \mathrm{min} / 1.73 \mathrm{~m}^{2}$

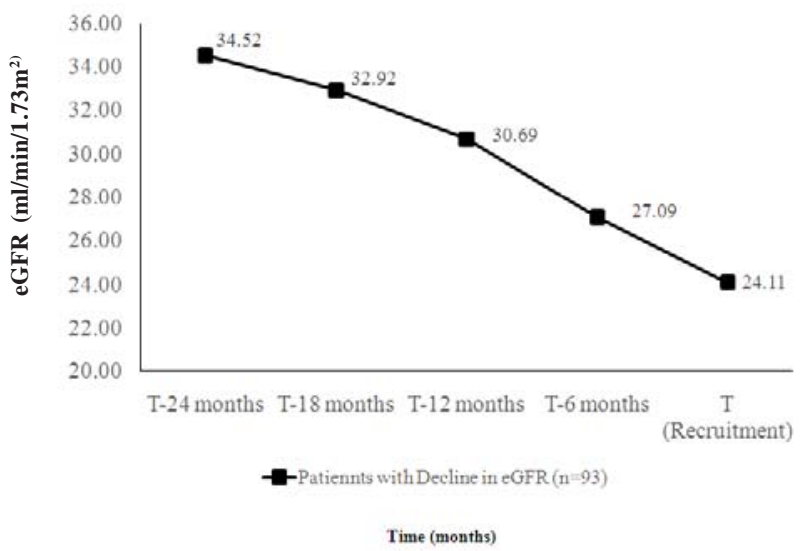

Figure 1. Average decline in eGFR with time among study participants.

\section{Discussion}

To the best of our knowledge the present study is the first to evaluate the progression of kidney disease in a cohort of patients with DN in Sri Lanka. We examined the decline in kidney function and factors associated with it, using a retrospective analytical method in a cohort of patients with DN attending a large tertiary care center in the capital of Sri Lanka. Since patients with DN and renal impairment are often followed up routinely in similar tertiary care settings within the country, we believe our findings are generalizable to the Sri Lankan population, within the context of limitations described.

In the present cohort, majority of patients were in CKD stage 3 and 4, with our results showing a decline in renal function in a significant majority (60.0\%) over a 24-month period. In a previous prospective follow-up study (3 years) conducted in a comparable clinical setting, the proportion of eGFR decliners in those with diabetes was only 30.1\%. ${ }^{17}$ Furthermore, in a larger cohort study $(n=1,868)$ from a similar setting with 2 years of follow-up, the percentage decline in eGFR of $-20 \%,-30 \%,-40 \%$ and $-50 \%$ was observed in only $23.9 \%, 11.1 \%, 6.8 \%$ and $3.7 \%$ respectively. ${ }^{18}$ This is much lower than the values observed for the percentage decline in each of the corresponding categories in the present study. In addition, in patients with declining eGFR the mean decline in eGFR per year was $5.2 \mathrm{ml} /$ $\mathrm{min} / 1.73 \mathrm{~m}^{2}$ with nearly one third of the study population demonstrating a rapid decline in kidney function. The annual decline in eGFR from most of the previous cohort studies among patients with DN appears to be much lower than what was observed in the present study population. For example, Ali et al, showed that the annual decline in eGFR is $1.69 \mathrm{ml} / \mathrm{min} .1 .73 \mathrm{~m}^{2}(95 \%$ Cl 1.53-1.84) in 329 patients with diabetic kidney disease from UK, with no significant changes observed in the decline of kidney function between the different ethnicities. ${ }^{19}$ The annual age-sex-adjusted rate of eGFR decline was even lower in a study comprising of 6,274 adults with diabetes and kidney disease followed up for a median of 9 years. ${ }^{20}$ Altemtam et al. conducting a similar retrospective analysis of medical records spanning 8 years from a single study center in UK, demonstrated that the decline in eGFR is $3.57 \pm 1.45$ $\mathrm{mL} / \mathrm{min} / 1.73 \mathrm{~m}^{2}$ per year. ${ }^{21}$ Therefore, it is evident that a much more rapid decline in kidney function is observed in the present study population and reasons for such differences needs to be further explored. 
In the context of the present cohort except advanced age, other socio-demographic, clinical or biochemical parameters didn't demonstrate a significant association with the decline in kidney function. However, previous studies have demonstrated a host of modifiable factors which are known to reduce the progression of kidney disease in those with DN, most of which are also relevant to the Sri Lankan population. Smoking is one such modifiable risk factor, which increases oxidative stress, lipid accumulation and formation of Advanced Glycation End products (AGEs), leading to thickening of glomerular basement membrane and mesangial expansion, with resultant progression in glomerulosclerosis. ${ }^{22} \mathrm{~A}$ recent metaanalysis has shown that cigarette smoking is an independent risk factor for the development and progression of DN in diabetes. ${ }^{23}$ In the present study we did not find a significant association. However, nearly $70 \%$ of the study population were never smokers, and there were only 2 current smokers. Furthermore, in the population who were never smokers $(n=47)$, $>95 \%$ were ex-smokers, with nearly $75 \%$ stopping smoking more than 10 years ago, which probably explains the lack of clear association seen in our study population.

Glycaemic control is another important disease modifier. Studies have shown that hyperglycaemia contributes to both the onset and the progression of DN as well as the rate of decline in kidney function. The cellular mechanisms responsible include accelerated generation of AGEs, which triggers increases in protein kinase activity and expression of growth factors, resulting in the generation of reactive oxygen species (ROS) and a state of a chronic subacute inflammatory process driving the pathological changes in the kidney and the decline in its function. ${ }^{24}$ However, in the present study population we did not observe a clear relationship between glycaemic control assessed by average fasting blood glucose and the decline in kidney function. Due to the inherent nature of the study design, fasting blood glucose estimations were done at different time points, with a high degree of variability. Furthermore, although a better indicator of long-term glycaemic control, HbA1c data were not available in majority of the study population to make a reasonable judgment of its relationship with the decline in eGFR. Hypertension is another risk factor that leads to increased progression of kidney disease and contributes to the increased incidence of cardiovascular disease in those with $\mathrm{DN} .{ }^{25}$ It is clear that elevations in blood pressure (BP), especially $>150 \mathrm{mmHg}$ systolic, are linearly related to increases in kidney disease progression. ${ }^{26}$ In the present study cohort, no clear association was seen between decline in kidney function and the presence of hypertension, its duration and average blood pressure values. The relatively small sample size, variations in measurement equipment, time-points, and observers, are few possible reasons for not seeing a clear relationship on statistical analysis. However, we observed that the percentage of population achieving recommended blood pressure control targets were sub-optimal in our population and based on those with HbA1c data, glycaemic control was also not satisfactory. The sub-optimal glycaemic and BP control could have contributed to the rapid decline in kidney function observed in the present cohort. Therefore, the importance of good glycaemic and blood pressure control as disease modifiers in DN should not be discounted, despite not seeing a clear statistical relationship in this population. Prescribers need to explore the reasons for not achieving optimal control in spite of being on appropriate medications among individual patients, and nonadherence needs to be carefully explored. For example a previous meta-analysis showed that non-adherence to antihypertensive medications was noticed in $45 \%$ of the subjects studied and a higher proportion of patients with uncontrolled blood pressure (83.7\%) was non-adherent to medication. ${ }^{27}$ Similar results have also been observed in relation to the use of anti-diabetic medications and glycaemic control. ${ }^{28}$ Other factors that contribute to poor glycemic and blood pressure control includes the clinical inertia among health care providers and the poor patient adherence to self-care recommendations, such as diet and physical activity, which health care providers need to carefully consider and manage.

Evidence from systematic reviews and metaanalysis have shown that certain medications are beneficial in DN, these includes, SGLT2 inhibitors ${ }^{29}$, ACEIs/ARBs30 and statins. ${ }^{31}$ The observed beneficial effects are possibly due to multiple factors, including the improvement in glycaemic control, reduction in blood pressure and proteinuria, which helps to slow down the aetio-pathological mechanisms driving the progression of kidney disease at cellular and tissue levels. For example, the use of ACEIs/ARBs were only observed in $67.7 \%$ of our study population. Therefore, the sub-optimal use of reno-protective medications could have contributed to the decline in renal function in the present cohort and it is important to initiate these medications as and when indicated in patients with DN. Although, we did not observe a clear relationship between the use of any medication and the decline in eGFR in our study population, it is important to consider that the duration of retrospective analysis is only 24 months, and that the different medications have been commenced at variable time-points, limiting the ability for a reasonable comparison, especially given the limitation in sample size. 
We acknowledge important limitations, which should be considered when interpreting results from the present study. The study reports data on a limited number of patients from a single center in Sri Lanka. However, as explained earlier since majority of DN patients are likely to be managed at similar centers in the country, our results are mostly generalizable to the Sri Lankan population with DN. Furthermore, due to inherent limitations of the study design, a clear cause-effect relationship is not evident for most established traditional modifiable risk factors that are known to be associated with the progression of kidney disease in DN. In addition, we did not specifically attempt to distinguish between the types of diabetes. However, given the fact that the age range of the population was 40-88 years and the youngest age of diagnosis of diabetes was 26 in the study population, together with the fact that $>75 \%$ of the study population were diagnosed with diabetes after the age of 40 years, combined with the fact that majority of the Sri Lankan population based on present evidence are having type2 diabetes, it is reasonable to assume that the present cohort is comprised of patients with type-2 diabetes. Finally we did not evaluate all risk factors known to be associated with progression of kidney disease previously described in the literature (e.g nephrotoxins). In spite of these limitations the study present significant findings with regards to the progression of DN in Sri Lanka. The observed rapid decline in eGFR will have negative long-term consequences for both the individual patients and the health care system as a whole. For example, if the decline continued at the present rate most patients in CKD stages of 3 and 4 in present cohort would have end-stage kidney disease requiring renal replacement therapy or transplantation within 510 years, placing an enormous burden on the already resource constrained health care system in Sri Lanka. Therefore, it is important to evaluate and modify factors that are associated with disease progression. In addition, the rapid decline in kidney function is an important factor that should be taken into account when taking policy decisions in relation to future preventive and curative health care planning aimed at patients with DN.

\section{Conclusions}

A rapid decline in kidney function was observed in the present study population. The observed rapid decline in eGFR will have negative long-term consequences for both the individual patients and the health care system. Therefore, it is an important factor that should be taken into account when taking policy decisions in relation to future preventive and curative health care planning aimed at patients with diabetic nephropathy.

\section{Declarations}

\section{Data availability} author.

Can be obtained by contacting the corresponding

\section{Competing interests}

Authors declare that they have no competing interests.

\section{Funding statement}

This study was funded by the Centre for Kidney Research, University of Sri Jayewardenepura, Sri Lanka.

\section{Acknowledgements}

None.

\section{Authors' Contribution}

$\mathrm{KW}, \mathrm{CG}, \mathrm{PdS}$, and $\mathrm{CH}$ made substantial contribution to conception and study design. KW and CG were involved in data collection. KW and PR were involved in refining the study design, statistical analysis and drafting the manuscript. KW, CG, PdS, PR and $\mathrm{CH}$ critically revised the manuscript. All authors read and approved the final manuscript.

\section{References}

1. Saeedi P, Petersohn I, Salpea P, et al. Global and regional diabetes prevalence estimates for 2019 and projections for 2030 and 2045: Results from the International Diabetes Federation Diabetes Atlas, 9(th) edition. Diabetes Res Clin Pract. 2019; 157: 107843.

2. Bergrem H, Leivestad T. Diabetic nephropathy and end-stage renal failure: the Norwegian story. Adv Ren Replace Ther. 2001; 8(1): 4-12.

3. Collins AJ, Foley RN, Gilbertson DT, Chen SC. United States Renal Data System public health surveillance of chronic kidney disease and end-stage renal disease. Kidney Int Suppl. 2015; 5(1): 2-7. doi: 10.1038/kisup.2015.2.

4. Gheith O, Farouk N, Nampoory N, Halim MA, Al-Otaibi T. Diabetic kidney disease: worldwide difference of prevalence and risk factors. J Nephropharmacol. 2015; 5(1): 49-56.

5. Young BA, Maynard C, Boyko EJ, Racial differences in diabetic nephropathy, cardiovascular disease, and mortality in a national population of veterans. Diabetes Care 2003; 26(8): 2392-9.

6. UK Prospective Diabetes Study (UKPDS) Group. Intensive blood-glucose control with sulphonylureas or insulin compared with conventional treatment and risk of complications in patients with type 2 diabetes (UKPDS 33). Lancet 1998; 352(9131): 837-53. 
7. Zhang Y, He D, Zhang W, et al. ACE Inhibitor Benefit to Kidney and Cardiovascular Outcomes for Patients with NonDialysis Chronic Kidney Disease Stages 3-5: A Network Meta-Analysis of Randomised Clinical Trials. Drugs 2020; 80(8): 797-811.

8. Caramori ML, Fioretto P, Mauer M, The need for early predictors of diabetic nephropathy risk: is albumin excretion rate sufficient? Diabetes 2000; 49(9): 1399-408.

9. Ritz E, Zeng X, Diabetic nephropathy-Epidemiology in Asia and the current state of treatment. Indian J Nephrol 2011. 21(2): 75-84.

10. Katulanda P, Sheriff MH, Matthews DR. The diabetes epidemic in Sri Lanka - a growing problem. Ceylon Med J. 2006; 51(1): 26-8.

11. The World Bank. Sri Lanka at a Glance. 2021 05/12/2021]; Available from: https://www.worldbank.org/en/country/ srilanka/overview\#1

12. Wanigasuriya K. Aetiological factors of Chronic Kidney Disease in the North Central Province of Sri Lanka: A review of evidence to-date. Journal of the College of Community Physicians of Sri Lanka 2012; 17(1): 21-42.

13. Young BA, Maynard C, Boyko EJ. Racial Differences in Diabetic Nephropathy, Cardiovascular Disease, and Mortality in a National Population of Veterans. Diabetes Care 2003; 26(8): 2392.

14. Selby NM, MW Taal. An updated overview of diabetic nephropathy: Diagnosis, prognosis, treatment goals and latest guidelines. Diabetes, Obesity and Metabolism 2020; 22(S1): 3-15.

15. Levey AS, Stevens LA, Schmid CH, et al. A new equation to estimate glomerular filtration rate. Annals of Internal Medicine. 2009; 150(9): 604-12.

16. National Kidney Foundation, K/DOQI clinical practice guidelines for chronic kidney disease: evaluation, classification, and stratification. Am J Kidney Dis. 2002; 39(2 Suppl 1): S1-266.

17. Yokoyama H, Kanno S, Takahashi S, et al. Determinants of decline in glomerular filtration rate in nonproteinuric subjects with or without diabetes and hypertension. Clin J Am Soc Nephrol. 2009; 4(9): 1432-40.

18. Oshima M, Toyama T, Haneda M, et al. Estimated glomerular filtration rate decline and risk of end-stage renal disease in type 2 diabetes. PLoS One. 2018; 13(8): e0201535. doi: 10.1371/journal.pone.0201535

19. Ali O, Mohiuddin A, Mathur R, Dreyer G, Hull S, Yaqoob MM. A cohort study on the rate of progression of diabetic chronic kidney disease in different ethnic groups. BMJ Open 2013; 3(2): e001855.

20. Mathur R, Dreyer G,Yaqoob MM, Hull S. Ethnic differences in the progression of chronic kidney disease and risk of death in a UK diabetic population: an observational cohort study. BMJ Open 2018; 8(3): e020145.

21. Altemtam N, Russell J, El Nahas M. A study of the natural history of diabetic kidney disease (DKD). Nephrol Dial Transplant. 2012; 27(5): 1847-54.

22. Chakkarwar VA. Smoking in diabetic nephropathy: sparks in the fuel tank? World J Diabetes 2012; 3(12): 186-95.

23. Jiang $N$, Huang $F$, Zhang $X$. Smoking and the risk of diabetic nephropathy in patients with type 1 and type 2 diabetes: a meta-analysis of observational studies. Oncotarget 2017; 8(54): 93209-18.

24. Maclsaac RJ, Jerums G. Ekinci El. Effects of glycaemic management on diabetic kidney disease. World J Diabetes 2017; 8(5): 172-86.

25. Van Buren PN, Toto R. Hypertension in diabetic nephropathy: epidemiology, mechanisms, and management. Adv Chronic Kidney D. 2011; 18(1): 28-41.

26. Patney VA, Whaley-Connell A, Bakris G. Hypertension Management in Diabetic Kidney Disease. Diabetes Spectrum 2015; 28(3): 175-80.

27. Abegaz TM, Shehab A, Gebreyohannes EA, Bhagavathula AS, Asim Ahmed Elnour AA. Nonadherence to antihypertensive drugs: A systematic review and meta-analysis. Medicine 2017; 96(4): e5641.

28. Polonsky WH, Henry RR. Poor medication adherence in type 2 diabetes: recognizing the scope of the problem and its key contributors. Patient Preference Adherence 2016; 10: 1299-1307.

29. Fleseriu M, Rosario Pivonello R, Elenkova A, et al. Efficacy and safety of levoketoconazole in the treatment of endogenous Cushing's syndrome (SONICS): a phase 3 , multicentre, open-label, single-arm trial. The Lancet Diabetes and Endocrinology 2019; 7(11): 855-65.

30. Cai J, Huang X, Zheng Z, Lin Q, Peng M, Shen D. Comparative efficacy of individual renin-angiotensin system inhibitors on major renal outcomes in diabetic kidney disease: a network meta-analysis. Nephrol Dial Transplant 2018; 33(11): 1968-76.

31. Shen X, Zhang Z, Zhang X, et al. Efficacy of statins in patients with diabetic nephropathy: a meta-analysis of randomized controlled trials. Lipids Health Dis. 2016; 15(1): 179. 